This is the final peer-reviewed accepted manuscript of:

Vecchi, A., Della Piana, B., \& Vivacqua, E. (2015). An institutional-based view of innovation-an explorative comparison of business groups in China and India. International Journal of Innovation Management, 19(05), 1550051.

The final published version is available online at:

https://doi.org/10.1142/S1363919615500516

Rights / License:

The terms and conditions for the reuse of this version of the manuscript are specified in the publishing policy. For all terms of use and more information see the publisher's website. 


\title{
AN INSTITUTIONAL-BASED VIEW OF INNOVATION- AN EXPLORATIVE COMPARISON OF BUSINESS GROUPS IN CHINA AND INDIA
}

\author{
VECCHI ALESSANDRA ${ }^{1}$ \\ Department of Management, University of Bologna, Italy \\ *alessandra.vecchi@unibo.it \\ DELLA PIANA BICE \\ Department of Management \& Information Technology, University of Salerno, Italy \\ bdellapiana@unisa.it \\ VIVACQUA ENRICA \\ Department of Management \& Information Technology, University of Salerno, Italy \\ evivacqua@unisa.it
}

\begin{abstract}
The aim of this explorative study is to compare the innovation performance of business groups in China and India in order to identify their distinctive local innovation dynamics. Data collection mainly relied on two sources: the world's 142 countries ranked by the Global Innovation Index Report (2013) which provides information about the countries' institutional settings and the Joint Research Centre Database listing the world's top firms ranked by their investments in Research and Development from which we gathered information about the business groups. From the findings, it emerges that not only that China overperforms India in relation to all the Innovation Indexes but that their distinctive institutional environments tend to favour very different dynamics of innovation. More precisely, while China's regulatory environment tends to support a more conservative approach of business groups towards investments in traditional sectors, India's lack of infrastructures coupled by a more efficient regulatory environment tend to support more resourceful and creative approach. These different approaches also shape the geographical distribution of business groups' innovation performance in the two countries.
\end{abstract}

Keywords: business groups, innovation, China, India, institutional-based view

\footnotetext{
${ }^{1}$ Corresponding author
} 


\section{Introduction}

The emergence of a knowledge-intensive society has changed the nature of business competition. Knowledge management becomes an important managerial task and formulating a sound innovation strategy is an integral part of strategic management (Luo et al., 2008). Drawing on our recent work on business groups (Della Piana et al. 2012a; Della Piana et al. 2012b; Vecchi et al., 2013) and on innovation (Crowe et al., 2007; Vecchi and Brennan, 2009a; Vecchi and Brennan, 2009b) and by endorsing an institution-based view in this paper we present an important yet understudied field of international management - the innovation performance of business groups across China and India. The relationship between business group affiliation and firm performance in emerging countries is attracting substantial interest (Khanna and Palepu, 2000; Khanna and Rivkin, 2001; Chacar and Vissa, 2005, Cuervo-Cazurra, 2006; Kedia et al., 2006; Gaur and Kumar, 2009; Zattoni et al., 2009; Choi et al., 2011; Hoskisson et al., 2013). With few exceptions (Peng, 2002; Peng and Delios, 2006; Khanna and Yafeh, 2007; Kumar and Singh, 2008; Gaur and Kumar, 2009; Filatotchev et al., 2013), however studies have only marginally investigated whether different institutional environments could change the positive effect that business group affiliation has on firms' performance. This is a relevant question and has been mostly investigated in relation to the mid-range emerging economies of Korea (Mahmood and Mitchell, 2004) and Taiwan (Mahmood and Mitchell, 2004; Chang et al., 2006; Hsieh et al., 2010; Kim et al., 2013). Overall, given the ubiquity of business groups, it is important to understand how different institutional settings affect their innovation performance. This issue is critically important, especially when considering the economic and social development of mid-range emerging economies. To date, though, little research addresses the interface between business groups and innovation across the different institutional settings of China and India (Choi et al., 2011; Lu et al., 2013). As such, there is an opportunity to conduct valuable research. Drawing on our recent work on business groups (Della Piana et al., 2012a; Della Piana et al., 2012b) and on innovation (Crowe et al., 2007; Vecchi and Brennan, 2009a; Vecchi and Brennan, 2009b) by endorsing an institution-based view (Peng, 2002; Peng and Delios, 2006; Peng and Jiang, 2010; Luo et al., 2011) in this paper we assess the innovation performance of business groups in China and in India. The aim of this explorative study is to conduct some institutional analysis (Hollingworth, 2000) by mainly focussing on the formal institutions in order to compare the innovation performance of business groups in China and India as to identify their distinctive local innovation dynamics. To this end, this study focuses on the capabilities of these two countries to transform their inputs (Institutions, Human Capital \& Research, Infrastructure, Market Sophistication; Business Sophistication) into outputs (Knowledge \& Technology Outputs and Creative Outputs) as they have been identified by the Global Innovation Index Report (2013). Data collection mainly relied on two sources: the JRC Database listing the world's top firms ranked by their investments in R\&D from which we gathered information about the business groups and the world's 142 countries ranked by the Global Innovation Index Report (2013) from which provides information about the institutional settings of the two countries. The study is articulated in several sections. The second section illustrates the institution-based view. The third section outlines the importance of innovation performance for business groups. The fourth section illustrates the methods used to select the most innovative firms in China and in India and describes the data analysis. While the fifth section deals with the preliminary findings, the last section provides the conclusion, addresses the managerial implications of the findings, their limitations and highlight directions for future research.

\section{The institution-based view}

Institutional theory emphasizes the influence of socio-cultural norms and values, as well as the effect of law and the judicial system, on organizational structure and behaviour (North, 1990). Institutions are formal (such as political rules, economic rules, and contracts) and informal (such as codes of conduct, norms of behaviour, and convention) constraints that regulate economic activities and human behaviour. Informal constraints are embedded in a culture and play a role when formal constraints fail (North, 1990). The present study only focuses on the formal institutions of China and India.

Institutions limit the set of choices individuals and organizations have, thereby providing a stable structure for economic exchanges and reducing uncertainty (North, 1990). Institutions and the effectiveness of their enforcement determine the costs of a transaction. Effective institutions increase the benefits derived from cooperative solutions, while ineffective institutions increase the benefits derived from defection (North, 1991). Institutions evolve incrementally and the story of an economy's performance can be seen as a story of institutional evolution (North, 1990). According to this view, the national institutional context has a significant impact on the rules of competition, 
on the firm strategy and its performance; and a more efficient institutional context favours market exchanges and the growth of the national economy (North, 1990; Wan and Hoskisson, 2003). Peng and Pleggenkuhle-Miles (2009) identifies the emergence of the institution-based view as a third leading perspective in strategic management, the first two being the industry-based and resource-based views. They firstly review the roots of the institution-based view, and then articulate its two core propositions by outlining how this view contributes to the fundamental questions in strategy. Overall, they suggest that the institution-based view represents the third leg of a strategy tripod, overcomes the long-standing criticisms of the industry-based and resource-based views' lack of attention to contexts, and contributes significant new insights as part of the broader intellectual movement centered on new institutionalism (Peng, 2002; Peng and Delios, 2006). The influence of the environment has long been featured in the literature (Lawrence and Lorsch, 1969). However, research in strategic management has typically favoured a view, which focuses primarily on economic variables such as market demand and technological change (Dess and Beard, 1984). Until the mid-1990s, researchers have rarely looked beyond the environment to explore the interactions among institutions, organizations and their strategic choices (Narayanan and Fahey, 2005). Instead, a market-based institutional framework has been endorsed where formal institutions, such as laws and regulations, and informal institutions, such as cultures and norms, have been assumed of secondary importance. While some scholars argue that this treatment of informal institutions as background is insufficient to gain a deeper understanding of strategic behaviour in developed economies, its deficiency becomes even more striking when the strategy research starts to probe into the business landscape of emerging economies (Lau and Bruton, 2008). Coinciding with the rise of emerging economies in the global economy since the 1990s, increasingly researchers have become interested in these countries (Lyles and Salk, 1996; Tong et al., 2008). Possessing a number of theoretical tools to undertake their research, these scholars mainly choose to deploy an institutional perspective, which is believed to give them a competitive edge when seeking to advance strategy research on emerging economies (Wright et al., 2005). According to Peng and Pleggenkuhle-Miles (2009), the fact that an institutional perspective is the most frequently drawn upon theoretical tool speaks volumes about the particular validity of this perspective when seeking to better understand the unfolding competition in emerging economies. Within this context Luo et al. (2011) identify a sustained and systematic pattern of strategic management issues at country-level. In particular they explicate that a unique combination of country-level institutional, competitive and socio-cultural conditions work together with a set of distinctive capabilities or weaknesses for most firms, by thus incubating certain country-level patterns of corporate, business and international strategies adopted by most firms within the same country. To further illustrate their argument, they use the BRIC (Brazil, Russia, India and China) countries to showcase an overarching framework of comparative environments, comparative capabilities, and comparative strategies among firms operating in the BRIC countries. Similarly Luo et al. (2008) by adopting an institution-based view, they argue that the institutional environment in the Asia Pacific region plays a multi-faceted role behind firms' knowledge management and innovation strategy. Specifically, institutions impose rules for legitimacy, serve as a source of knowledge, and allocate incentives and resources for innovation. They believe that future research drawing on the institution-based view would possess significant potential to advance our understanding of knowledge management and innovation strategy in Asia Pacific firms. More recently, Hoskisson et al. (2013) argue that significant diversity of initial conditions, transition paths, and competitive outcomes have made it crucial to make distinctions within the encompassing label of 'emerging economies'. As the heterogeneity of developed economies is being increasingly researched, there is the need to recognize that 'emerging economies' are also not homogeneous. The authors claim that there is the need to enrich this single label to encompass more diversity as these economies present distinctive features. In particular they outline how, if the notion of 'emerging economies' is meaningful, over time some of the 64 countries identified by Hoskisson et al. (2000) should have progressed beyond their initial status. While some countries have undoubtedly stagnated, various emerging economies have increased both the development of their market institutions and the economic infrastructure to be considered 'mid-range emerging economies' between newly developed economies and traditional emerging economies. Within this context, according to Hoskisson et al. (2013) the BRIC countries can be classified in as mid-range emerging economies, although they specify that some significant differences within these countries still remain. In particular, according to this taxonomy mid-range economies are characterised by both high institutional development and low infrastructure development. For instance in China, Chinese acquisitions that tend to be undertaken by state-owned enterprises, often encounter significant suspicion in developed economies. Because stateowned enterprises are often perceived as manifestations of national interests, their local penetration in the host country is often obstructed due to concerns over national security. This anecdotal evidence strikes significantly with what happens in India that has relatively strong democratic political institutions that have often created obstruction at times hindering business development. Indian acquisitions in developed economies tend to be undertaken by private firms, which tend to be more receptive in host countries. As for the infrastructure development, according to Hoskisson $e t$ al. (2013) the lack of infrastructure development has stifled some industries. As a result, the Indian automobile 
industry is less developed domestically, although several Indian firms have made extensive acquisitions of foreign firms. However, the Indian automobile industry as a whole is significantly lagging behind the Chinese automobile industry. According to the authors, this is primarily because of India's poor transportation infrastructure. This leads Hoskisson et al. (2013) to conclude that new MNEs (Multi-National Enterprises) from mid-range emerging economies may internationalise to developed markets more easily due to a shorter institutional distance between MNEs from mid-range emerging economies and developed markets. In the light of this evidence and by endorsing this institutionbased framework we can safely assume that the dual effect of institutional development and infrastructure development in mid-range emerging economies not only is likely to have profound consequences for firms' internationalisation as found by Hoskisson et al. (2013) but also for their innovation performance.

\section{The Innovation performance of business groups}

Business groups are the dominant organizational form in mid-range emerging economies (Zattoni et al., 2009). A business group consists of individual firms with multiple links through which the firms are coordinated in order to achieve common goals (Granovetter, 1994). Although business group characteristics differ across countries (Gaur and Kumar, 2009; Kim et al., 2012; Ramaswami et al., 2012), according to Zattoni et al. (2009) business groups have two particular traits that distinguish them from other organizational forms. These are namely the existence of multiple ties among individual firms and the presence of an administrative center aimed at coordinating all the group-affiliated firms. There has been a growing interest amongst management scholars in this subject, especially in relation to emerging economies (Chang and Hong, 2002; Guillen, 2000; Keister, 1998; Khanna and Palepu, 2000; Khanna and Rivkin, 2001; Carney et al., 2009; Zattoni et al., 2009; Gaur and Kumar, 2009). In emerging economies, capital, labour and product markets are all characterised by high imperfections. Within this context, business groups are seen as organizational solutions for solving the problems that arise from an inadequate institutional environment (Khanna and Palepu, 2000; Kim et al., 2004; Carney et al., 2011; Ramaswamy et al., 2012; Kim et al., 2013). According to the institution-based view, business groups act as a substitute for the missing external institutions and they create an efficient business environment for affiliated firms (Gaur and Kumar, 2009; Zattoni et al., 2009). Previous studies of business groups have analyzed the relationship between business group affiliation and firm performance (Choi et al., 2011). Studies either compare the performance effects of business group affiliation across a number of emerging countries (Khanna and Rivkin, 2001) or compare the performance effects of business group affiliation in emerging and developed economies (Chacar and Vissa, 2005; Gaur and Kumar, 2009; Zattoni et al., 2009). With few exceptions (Kedia et al., 2006; Khanna and Palepu, 2000; Asakawa and Som, 2009; Dodgson, 2009; Soh and Yu, 2010), studies have not investigated whether different institutional environments could change the positive effect that business group affiliation has on firm performance (Khanna and Yafeh, 2007; Kumar and Singh, 2008; Gaur and Kumar, 2009). This is a relevant question, as different institutional settings modify the rules of the game and affect company behaviour and performance (North, 1990; Peng, 2003). In particular, of particular interest is the effects that business groups have on innovation in mid-range emerging economies. According to Choi and colleagues (2011), four important elements of innovation infrastructure can be made more accessible by business groups in a transition economy: capital, scientific-labour markets, knowledge sourcing, and vertical intermediation. First, business groups can act as venture capitalists for new innovation opportunities for firms that lack internal cash flow and external sources for funding. Second, business groups can play a crucial role as an incubator for talented scientists and the internal labour market by conducting research, engineering, vocational institutes and by providing specialised employment and training. Third, business groups in the form of strategic alliances and joint ventures, they can facilitate important technological relationships with foreign firms from developed countries and help domestic firms access advanced technology and develop critical tacit knowledge for innovation. Finally, business groups hold their own vertical intermediaries, such as suppliers and distributors, which are considered an important part of the innovation infrastructure.

According to Mahmood and Mitchell (2004) business groups in emerging economies exert dual effects on innovation. While business groups facilitate innovation by providing institutional infrastructure, they also discourage innovation by creating entry barriers for non-group firms and thereby inhibit the proliferation of new ideas. This pattern reflects an evolutionary process in which the interplay of the availability of innovation infrastructure and variety of ideas influences the level of innovation in an industry. The authors show that group market share has an inverted-U impact on innovation in industrial sectors of both Korea and Taiwan during the 1981-1995 period. From their findings, it emerges that the existing institutional differences between Korea and Taiwan in terms of market structure and industrial policies lead to different innovation thresholds, the point at which the marginal costs of increasing business groups' share begin to dominate the marginal benefits in the two countries. Chang et al. (2010) using a comparative institutional perspective, explore whether business groups' roles in facilitating affiliate firms' innovation varies by 
country and by time period. They compare the innovativeness of firms affiliated with business groups to that of independent firms in two emerging economies, South Korea and Taiwan. From their findings, it emerges that on average, business group affiliates outperform independent firms in South Korea, but not in Taiwan, and in the early 1990 s, but not in the late 1990s. The existence of alternative institutional infrastructures for innovation might explain these differences. Groups' abilities to share technological knowledge and financial resources among affiliates enables them to create value by promoting innovation in emerging economies, but groups' diversification might inhibit individual affiliates' innovativeness. Hsieh et al. (2010) further investigate the relationship between business group factors and affiliated firm innovation in terms of patents granted. They examine the following factors for business groups: group affiliation, group diversification, inside ownership, and family ties. In emerging markets, business groups act not only as an internal capital market, but also as a platform for resource sharing among affiliates. The authors use Taiwan's business groups as a research sample to investigate how these group factors affect affiliated firms' innovation. Their findings indicate that firms that are affiliated with business groups innovate better than their unaffiliated counterparts do. Group diversification and family ties have positive effects on firm innovation, while inside ownership has no significant positive effect. The study contributes to the innovation literature by shedding light on business group factors and firm innovation. Overall, given their ubiquity, it is important to understand how business groups affect innovation across different institutional settings, which is critically important to economic and social development in mid-range emerging economies. To date, though, little research addresses the interface between business groups and innovation in China and India. As such, there is the valuable opportunity to conduct further research. Drawing on our recent work on business groups (Della Piana et al., 2014; Della Piana et al., 2012a; Della Piana et al., 2012b) and on innovation (Crowe et al., 2007; Vecchi et al., 2014c; Vecchi and Brennan, 2009a; Vecchi and Brennan, 2009b) by endorsing an institution-based view (Peng et al., 2010; Luo et al., 2011) we assess the innovation performance of business groups across China and India to identify their distinctive local innovation dynamics. In line with Hoskisson et al. (2013) the underlying assumption is that the dual effect of institutional development and infrastructure development in mid-range emerging economies is likely to have profound consequences for business groups' innovation performance.

\section{Methodology}

The aim of this explorative study is to conduct an institutional analysis (Hollingsworth, 2000) by mainly focussing on the formal institutions in order to compare the innovation performance of business groups in China and India so to understand the extent to which innovation occurs in different institutional settings. In particular, we are keen to explore the relationship that there is between innovative firms and innovative countries to assess how different institutional settings allow innovation to thrive. By taking an institution-based view of innovation we endorse the idea that the innovative behaviour of firms is powered by a number of conditions that do not relate exclusively to internal resources or resources that are owned by them but these are grounded in socio-economic and cultural environment in which these firms operate (Peng et al., 2010; Luo et al., 2011). Our institutional perspective is mainly pitched at a national level, and the types of business groups we are considering are within a nation's boundaries. Thus, the level of analysis under consideration regards institutional analysis involving multiple levels and their innovation performance. According to Hollingsworth (2000) the main components of institutional analysis are the institutions (norms, rules, conventions, habits and values), the institutional arrangements (markets, states, corporate hierarchies, networks, associations, communities), the institutional sectors (financial system, system of education, business system, system of research), the organizations and the outputs and the performance (statutes; administrative decisions, the nature, quantity and the quality of industrial products, sector and societal performance. More precisely, our analysis focusses on the institutional sectors (formal institutions) and the innovation performance since quantifiable data about these two parameters is widely available. To this end, data collection mainly relied on two sources: the world's 142 countries ranked by the Global Innovation Index (2013) from which provides information about China and India and their institutional sectors and the Joint Research Centre (JCR) dataset listing the 1500 world's top innovative firms ranked by their investments in R\&D from which we gathered information about Chinese and Indian business groups' outputs and performance. These two sources are explained in more detail below.

The world's 141 countries ranked by the Global Innovation Index. Two important organizations INSEAD and the World Intellectual Property Organization (WIPO, a specialized agency of the United Nations) co-publish the Global Innovation Index (GII) since 2012. The GII that was previously published by INSEAD and it is now in its fifth edition. The GII provides valuable guidance to assess the key role of innovation as a driver of economic growth for emerging countries. The method used relies on the Global Innovation System (GIS) that provides composite indicators that are apt to classify in rankings the most innovative countries of the world by considering their relevant institutional sectors. 
Stemming from the premise that innovation is an important driver for economic progress both for firms and for countries development, the GIS relies on the GII specific indexes and sub-indexes that identify different levels of innovation of the countries. To the purpose of this work, secondary data was collected from the latest GII Report 2013 and it is relies on four of its sub-indexes, the Innovation Input Sub-Index, the Innovation Output Sub-Index, the Global Innovation Index and the Innovation Efficiency Ratio.

\begin{tabular}{|l|l|}
\hline \multicolumn{2}{|l|}{ Table 1: GII Report 2013 and its main Indexes } \\
\hline Index & $\begin{array}{l}\text { GII Pillars } \\
\text { Market Sophistication, and Business Sophistication }\end{array}$ \\
\hline Innovation Input Sub-Index & $\begin{array}{l}\text { Knowledge \& Technology Outputs and Creative } \\
\text { Outputs }\end{array}$ \\
\hline Innovation Output Sub-Index & Simple average of the Input and Output Sub-Indices \\
\hline Global Innovation Index & $\begin{array}{l}\text { The ratio of the Output Sub- Index over the Input Sub- } \\
\text { Index }\end{array}$ \\
\hline
\end{tabular}

Five input pillars capture the key elements of the national economy that tend to enable innovative activities. These are namely, Institutions, Human Capital \& Research, Infrastructure, Market Sophistication, and Business Sophistication. Two output pillars capture the actual evidence of innovation outputs. These are namely, Knowledge \& Technology Outputs and Creative Outputs. Each pillar is divided into several sub-pillars and each sub-pillar consists of several individual indicators. Sub-pillar scores are calculated as the weighted average of the individual indicators; pillar scores are calculated as the weighted average of sub-pillar scores. In the 2013, 142 countries are ranked by 84 indicators (60 hard data, 19 composit indexes, 5 soft data in the form of survey questions). The Innovation Input Sub-Index is the simple average of the first five pillar scores. The Innovation Output Sub- Index is the simple average of the last two pillar scores. The Global Innovation Index is the simple average of the Input and Output Sub-Indices. The Innovation Efficiency Ratio is the ratio of the Output Sub- Index over the Input Sub-Index.

The world's top firms ranked by their investments in $R \& D$. Data collection on Chinese and Indian business groups relied on a very robust sampling frame as it relied the Joint Research Centre (JCR) dataset listing the 1500 world's top innovative firms ranked by their investments in R\&D. The dataset belongs to the JRC, which in turn depends on the Directorate General for Research and Innovation of the European Commission and contains accurate socio-economic and financial information in relation the firms ranked. It consists of a sample of 1500 firms (405 based in the $\mathrm{EU}^{2}$, 1095 in non-EU countries ${ }^{3}$ ) with R\&D investments above $€ 34.9$ million across 37 sectors $^{4}$ and were therefore deemed

${ }^{2}$ These firms were based in the following countries: DE 108; UK 81; FR 58; SE 26; NL 24; IT 23; DK 21; ES 15; FI 14; BE 12; EI 8; AU 7; PO 4; LU 4; HU 2; SI 1; CZ 1.

${ }^{3}$ These firms were based in the following countries: US 503; Japan 296; China 56; Taiwan 47; Switzerland 40; South Korea 35; Cayman Islands 22; India 15; Australia 12, Canada 11, Brazil 7 and further 19 countries.

${ }^{4}$ The sectors of the firms ranked in the JRC Scoreboard 2012 are the following: Aerospace \& Defense; Alternative Energy, Automobiles \& Parts; Banks; Beverages; Chemicals; Construction \& Materials; Electricity; Electrical equipment; Fixed line telecommunication; Food \& Drugs Retailers; Food Producers; Forestry \& Paper; Gas, Water \& Multi-utilities; General Industrial; General Retailers; Health Care Equipment Services; Household Good \& Home Construction; Industrial Engineering; Industrial Metals \& Mining; Industrial Transportation; Leisure Goods; Life Insurance; Media; Mining; Mobile telecommunication; Nonlife Insurance; Oil \& Gas Producers; Oil Equipment Service and Distribution; Other Financials; Personal Goods; Pharmaceuticals \& Biotechnology; Software \& Component Services; Support Services; Technology Hardware Equipment; Tobacco; Travel \& Leisure. While the JRC Scoreboard 2011 contains information about the 1400 Best World Companies, in 2010, 2009 and 2008 the JRC data refers to EU and non-EU Industrial R\&D and presents information on 2000 firms around the world reporting major investments in R\&D. The total number of sectors in these years is 45 . These are: Oil \& Gas Producers; Oil 
by JCR as being the most innovative firms. To the purpose of our paper, data collection relies on the most recent EU Industrial R\&D Scoreboard available (2012), where for each firm ranked on the Scoreboard we individually verified the identity of the members sitting on the firm's Executive Board and whether the company was a parent or a subsidiary of a business group by thus identifying 1500 business groups. In order to maximize completeness and avoid any possible double counting, only the consolidate group accounts of the administrative centers were considered. Despite being aware that the examination of innovation capacity needs, as highlighted by Forsman (2011), the consideration of at least three variables such as internal resources, capabilities and the external input gained through networking, our study in line with the JCR dataset only focuses on the level of investments in R\&D. Innovation is defined as "creating something new and implementing it successfully at a market" (Brown and Ulijn, 2004). Innovation capabilities represent the capacity to identify the most appropriate resources, to select them and to recombine them in order to gain a sustainable competitive advantage. Within this context, R\&D investments can be usefully considered as a "blue print" on firm's innovation capacity (Della Piana and Vivacqua, 2012). The literature usually takes R\&D expenditures primarily as an input indicator and the patent data as an output indicator; these indicators can be used individually or combined to measure firms' innovative performance (Hagedoorn and Schakenraad, 1990; Cloodt, 2003). Similarly, R\&D expenditures are also relevant for comparing productivity measures for firms as well as for countries (Griffith et al., 2000). Specifically, to measure R\&D intensity for a firm, it is usually adopted the R\&D/Sales ratio, and also often it is possible to use the ratio between Business Expenditure and R\&D (BERD) (Sandven and Smith, 1997). To the purpose of this paper, while the R\&D investment is the cash investment that is funded by the business group itself $f^{5}$, BERD refers to all R\&D activities performed by the business groups within a particular sector and territory, regardless of the location of the administrative center and regardless of the source of finance. Business groups' country of origin is defined by the country in which their administrative center is registered. In many cases, this is differently located from the operational or the R\&D center. Despite of the different location that administrative and $R \& D$ centers might have, we assume that the location of the administrative center as reported in the Scoreboard can be regarded as the place where strategic decisions are made in relation to the R\&D activities (Hoskisson and Hitt, 1998; Baysinger et al., 1991).

\section{Data analysis}

To assess the influence of institutional settings on innovation performance we cross-referenced the data obtained from the latest GII Report which provides the rankings in 2013 for India and China with the data obtained from the JCR that identifies the most innovative business groups in 2012. Given that the aim of the paper is to conduct a thorough institutional analysis (Hollingsworth, 2000) by focussing on the formal institutions as to compare the innovation performance of business groups in China and India. In order to understand the extent to which innovation occurs in different institutional settings, we compared China and India on the basis of their respective Innovation Input SubIndex, the Innovation Output Sub-Index, the Global Innovation Index and the Innovation Efficiency Ratio. Each Index, Sub-Index and the relevant individual sub-pillar score are presented on a scale from 0 to 100 (with 0 being the lowest score and 100 the highest). The Innovation Efficiency Ratio ranges from 0 to 1 (with 0 considered lack of efficiency and 1 considered the highest efficiency). The rankings range from 1 to 142 (the highest ranking). Drawing on the JCR dataset we then considered the most innovative firms in China and India according to their sectoral and geographical distribution. These two aspects were illustrated in relation to their institutional environments as they were ranked by the GII Report 2013. This allowed us to provide in-depth insights over the local dynamics of innovation in these two mid-range emerging countries.

Equipment, Services \& Distribution; Alternative Energy; Chemicals; Forestry \& Paper; Industrial Metals; Mining; Construction \& Materials; Aerospace \& Defence; General Industrials; Industrial Transportation; Support Services; Automobiles \& Parts; Beverages; Food Producers; Household Goods; Leisure Goods; Personal Goods; Tobacco; Health Care Equipment \& Services; Food \& Drug Retailers; General Retailers; Media; Travel \& Leisure; Fixed line Telecommunications; Mobile Telecommunications; Electricity; Gas, Water \& Multi-utilities; Banks; Nonlife Insurance; Life Insurance; Other Financials; Electrical Components \& Equipment; Electronic Equipment; Commercial vehicles \& Trucks; Industrial machinery; Biotechnology; Pharmaceuticals; Computer Services; Internet; Software; Computer Hardware; Electronic Office Equipment; Semiconductors; Telecommunications Equipment.

${ }^{5}$ It excludes R\&D undertaken under contract for customers such as governments or other companies; it also excludes the companies' share in any associated company or joint venture R\&D investment when these are disclosed. Where part or all of R\&D costs have been capitalized, the addictions to the appropriate intangible assets are included to calculate the cash investment and any amortization has been eliminated. 


\section{Preliminary Findings}

\section{Innovation in China and India}

As shown in Table 2, China and India are by far the world's two most populous countries, with 1.37 million and 1.26 million inhabitants respectively. China is the "workshop of the world" and its GDP is 8.25 billions, it belongs to the upper-middle income group in South East Asia. India excels in skill-intensive services and its GDP is 1.94 billions, it belongs to the lower-middle income group in Central and Southern Asia (GII, 2013).

\begin{tabular}{|l|l|l|}
\hline \multicolumn{2}{|l|}{ Table 2: Key-Indicators for China and India } \\
\hline & China & India \\
\hline Population (millions) & $1,374.0$ & $1,267.6$ \\
\hline GDP (US\$ billions) & $8,250.2$ & $1,946.8$ \\
\hline GDP per capita, PPP\$ & $9,146.4$ & $3,851.3$ \\
\hline Income group & Upper-middle income & Lower-middle income \\
\hline Region & South East Asia and Oceania & Central and Southern Asia \\
\hline Source: Global Innovation Report 2013 \\
\hline
\end{tabular}

From the analysis of the GII 2013 data, as illustrated in Table 3, it emerges that while China overperforms India in relation to all the innovation indexes, it underperforms India in relation to the Innovation Efficiency Ratio.

\begin{tabular}{|l|c|c|c|c|}
\hline \multicolumn{1}{|c|}{ Table 3: Innovation for China and India } & \multicolumn{2}{c|}{ India } \\
\hline & Score & Rank & Score & Rank \\
\hline Global Innovation Index 2013 & 44,70 & $\mathbf{3 5}$ & 36,2 & 66 \\
\hline Innovation Output Sub-Index & 44,10 & $\mathbf{2 5}$ & 36,60 & 42 \\
\hline Innovation Input Sub-Index & 45,20 & $\mathbf{4 6}$ & 35,80 & 87 \\
\hline Innovation Efficiency Ratio & $\mathbf{1 , 0 0}$ & 14 & $\mathbf{1 , 0 0}$ & $\mathbf{1 1}$ \\
\hline Global Innovation Index 2012 & 45,40 & $\mathbf{3 4}$ & 35,70 & 64 \\
\hline Source: Global Innovation Report 2013 & \multicolumn{4}{|}{} \\
\hline
\end{tabular}

By comparing the rankings in GII from 2012 to 2013 it emerges that all the BRICs have experienced a relative stagnation or mostly a drop in innovation rankings: China (35th; a decrease of one spot from 2012 and six from 2011), the Russian Federation (62nd; a decrease of 11 positions from 2012 and six from 2011), Brazil (64th; a decrease of six spots from 2012 and 17 from 2011), and India (66th; a decrease of two positions from 2012 and four from 2011). The Innovation Efficiency Ratio provides an indication of those economies that have 'achieved more with less' and those that lag behind in terms of fulfilling their innovation potential. In theory, assuming that innovation results go hand in hand with innovation enablers, the efficiency ratio should be equal to 1 . This is the case both for China and for India. This measure thus allows us to complement the GII by providing an insight that should be neutral to the different developmental stages of these two economies. Both China and India demonstrate superior levels of innovation output compared with other countries with similar income levels. Their progress, however is not homogeneous, and presents significant differences. If we look at the Innovation Input Sub-Index for both countries in Table 4, again China overperforms India in relation to all pillars except for the Institutions' pillar.

\begin{tabular}{|l|c|c|c|c|}
\hline Table 4: The Innovation Input Sub-Index for China and India \\
\hline & \multicolumn{2}{|c|}{ China } & \multicolumn{2}{c|}{ India } \\
\hline The Innovation Input Sub-Index & Score & Rank & Score & Rank \\
\hline Institutions & 48,30 & 113 & 51,90 & $\mathbf{1 0 2}$ \\
\hline Human Capital \& Research & 40,60 & $\mathbf{3 6}$ & 21,70 & 105 \\
\hline Infrastructure & 39,80 & $\mathbf{4 4}$ & 27,50 & 89 \\
\hline
\end{tabular}




\begin{tabular}{|l|c|c|c|c|}
\hline Market Sophistication & 54,20 & $\mathbf{3 5}$ & 49,50 & 49 \\
\hline Business Sophistication & 42,90 & $\mathbf{3 3}$ & 28,30 & 94 \\
\hline Innovation Output Sub- Index & Score & Rank & Score & Rank \\
\hline Knowledge \& Technology Outputs & 56,40 & $\mathbf{2}$ & 34,50 & 37 \\
\hline Creative Outputs & 31,90 & 96 & 38,60 & 65 \\
\hline Source: Global Innovation Report 2013 & \multicolumn{4}{|l}{} \\
\hline
\end{tabular}

The first sub-index of the GII, the Innovation Input Sub-Index, has five enabler pillars: Institutions, Human Capital \& Research, Infrastructure, Market Sophistication, and Business Sophistication. Enabler pillars define aspects of the environment that are conducive to innovation within an economy. In this respect, China ranks better then India in relation to all the pillars except for the Institutions' pillar. As for the second sub-index of the GII, Innovation Outputs are the results of innovative activities within the economy. The Innovation Output Sub-Index includes only two pillars. These are namely Knowledge \& Technology Outputs and Creative Outputs where China ranks again better then India apart from Creative Output where India ranks 65. The GII results confirm that the eighteen emerging economies are overperforming their counterparts in their respective income groups: in terms of Innovation Output Sub-Index China and India respectively rank number 1 and number 2 in their group, namely the upper-middle income group (40 in total) and the lower-middle income (36 in total).

In China we can observe how local innovation thrives on the high rate of firms offering formal training (score 84.8) which makes China ranking at number 1 . Because of its education in mathematics and science, the country also ranks as the number 1 . The country ranks number 2 in terms of Gross Capital formation as a percentage of GDP (score 47.8). The country is also ranked as number 4 in terms of higher percentage of R\&D expenditure funded by the business sector (score 71.7). The country also ranks number 1 for domestic patent applications (score 36.8) and for the exports of creative goods (score 15.4). The country ranks number 2 for Knowledge \& Technology Outputs (score 56.4) and number 3 for Knowledge Creation (score 66.50). As Chinese companies become more competitive in innovation, they are increasingly bound to worry about potential obstacles to further innovation growth. Issues such as access to talent, retention of talent, and rapid cost increases are all key concerns for innovation in the future. The areas of concern include difficulties in understanding market needs, inadequate infrastructure and innovation ecosystems (i.e. innovation linkages present a relatively low score and a low ranking), and inadequate intellectual property protection which are particularly crucial in the health and life sciences industry. These worries are likely to increase pressure for stronger laws regarding intellectual property protection, and may well lead to more innovative ways to conduct R\&D in cooperation with universities, institutes, and other entities.

By contrast, in India we can observe how local innovation functions and adapts (Innovation Efficiency Ratio of 1 ranking 11) to an environment that is severely constrained by the resources available (Infrastructures score 27.5; ranking 89). Some of these inefficiencies are reflected in the country's current low R\&D expenditure in cutting-edge technology and basic sciences (score 30.9; ranking 30), its low rate of firms offering formal training (score 15.9; ranking 96), its education (score 27.60; ranking 127) and its low rate of knowledge absorption (score 16.5; ranking 122) to name a few. Despite of all these challenges, India has grown rapidly with its labour force that is inherently innovative and entrepreneurial, even if the innovations characterising the country have been, in some cases, temporary and makeshift. This pattern is also reflected in the countries' R\&D expenditures. As illustrated in Table 5, while China spends considerably more in R\&D by ranking at number 24 , India tends to spend relatively less by ranking at number 30 .

\begin{tabular}{|l|c|c|c|c|}
\hline Table 5: R\&D Expenditures for China and India & \multicolumn{2}{|c|}{ China } & \multicolumn{2}{c|}{ India } \\
\hline & Score & Rank & Score & Rank \\
\hline & 41,50 & $\mathbf{2 4}$ & 30,90 & 30 \\
\hline Research \& development (R\&D) & 84,80 & $\mathbf{1}$ & 15,90 & 96 \\
\hline Firms offering formal training, \% firms & 1,30 & $\mathbf{1 7}$ & 0,30 & 42 \\
\hline R\&D performed by business & 71,70 & $\mathbf{4}$ & 33,90 & 48 \\
\hline R\&D financed by business & 27,90 & 61 & 30,90 & $\mathbf{5 1}$ \\
\hline Innovation linkages & \multicolumn{4}{|}{} \\
\hline Source: Global Innovation Report 2013
\end{tabular}




\section{The most innovative business groups in China and India}

Drawing on the JCR data we then considered the most innovative firms in China and India according to their sectoral and geographical distribution. These two aspects were illustrated in relation to their institutional environments as they were ranked by the GII Report 2013. This allowed us to provide in-depth insights over the local dynamics of innovation in these two mid-range emerging countries. While 56 Chinese business groups were identified as being the most innovative according to the JCR Scoreboard (2012) in 2012 (as measured by their R\&D expenditure), only 14 Indian business groups that were identified as being the most innovative.

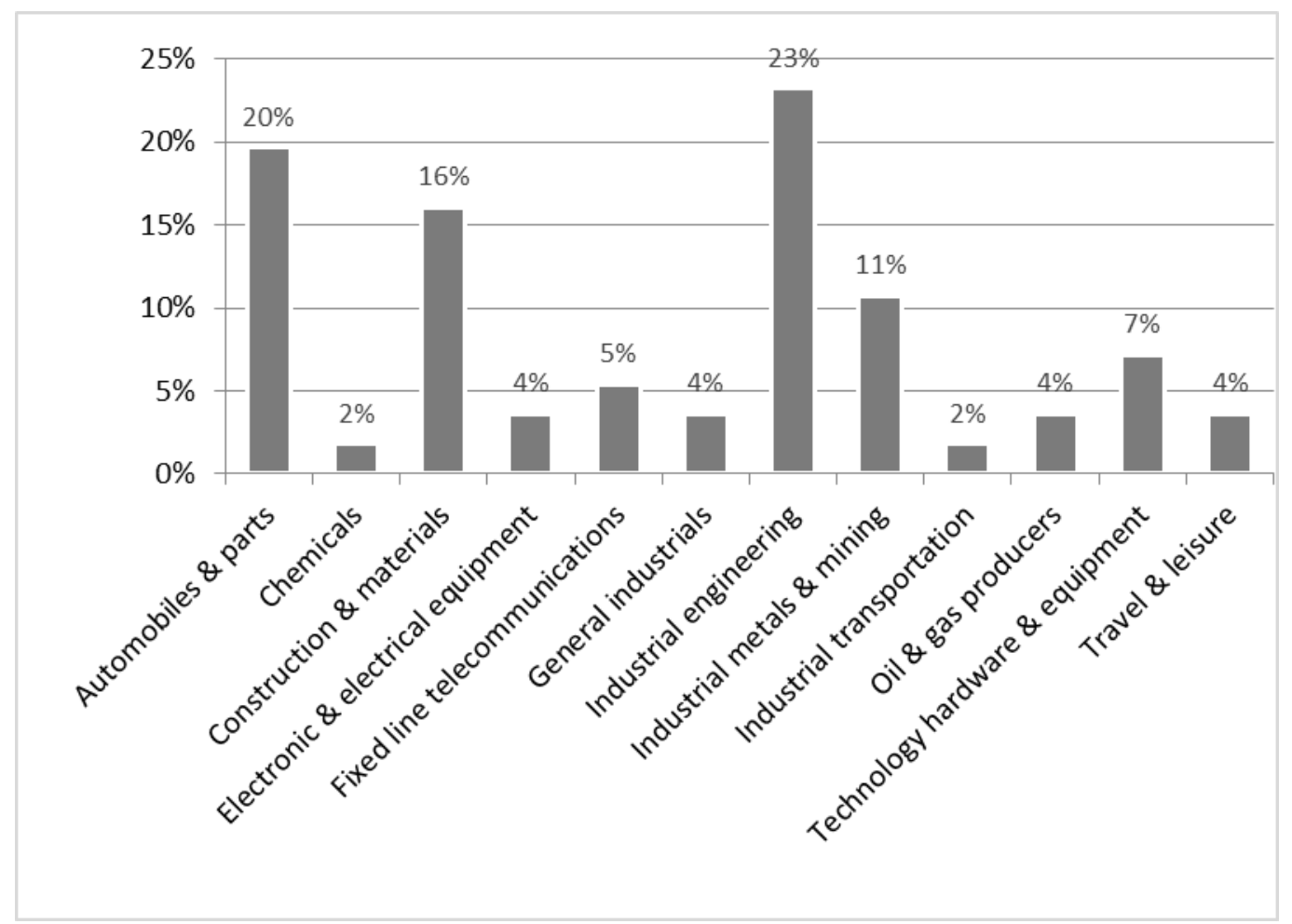

Figure 1: The most innovative Chinese business groups by sector (Source: JCR, 2012)

As illustrated in the Figure 1, in China the most innovative sectors are 4 (out of a total of 12 sectors) and these are namely Automobile \& Parts (11 firms), Construction \& Materials (9 firms), Industrial Engineering (13 firms) and Industrial Metals \& Mining (6 firms). Chinese firms have developed stronger manufacturing capability due to skilful labour force (firms offering formal training as a percentage of total firms score 84.80; ranking 1), inexpensive labour costs, improved infrastructure and logistics (infrastructure score 39.80; ranking 44), and increased technological awareness (Knowledge \& Technology Output score 56.40; ranking 2). Strong relationship capabilities are more important in China due to the legacy of transition economies and the strong power of government officials.

As illustrated in the Figure 2, in India the most innovative sectors are only two (out of 7 sectors in total): Pharmaceuticals \& Biotechnology (7 firms) and Industrial Engineering ( 2 firms). While China is the "workshop of the world", competitive in manufacturing, India is stronger in skill-intensive services. India's success in this area is largely due to the country's superb capabilities in IT-enabled services (online creativity score 17.50; ranking 105), language advantages (as it was a former British colony), and its ever-growing talent pool in IT. According to NASSCOM and McKinsey \& Company (2009), Indian business process outsourcing service providers have forged business relationships with $75 \%$ of Fortune 500 companies. The country has 2.5 million people working in the business process outsourcing industry, accounting for nearly $95 \%$ of the growth in foreign exchange inflows in services industries in recent years according to the Center for Monitoring the Indian Economy. 


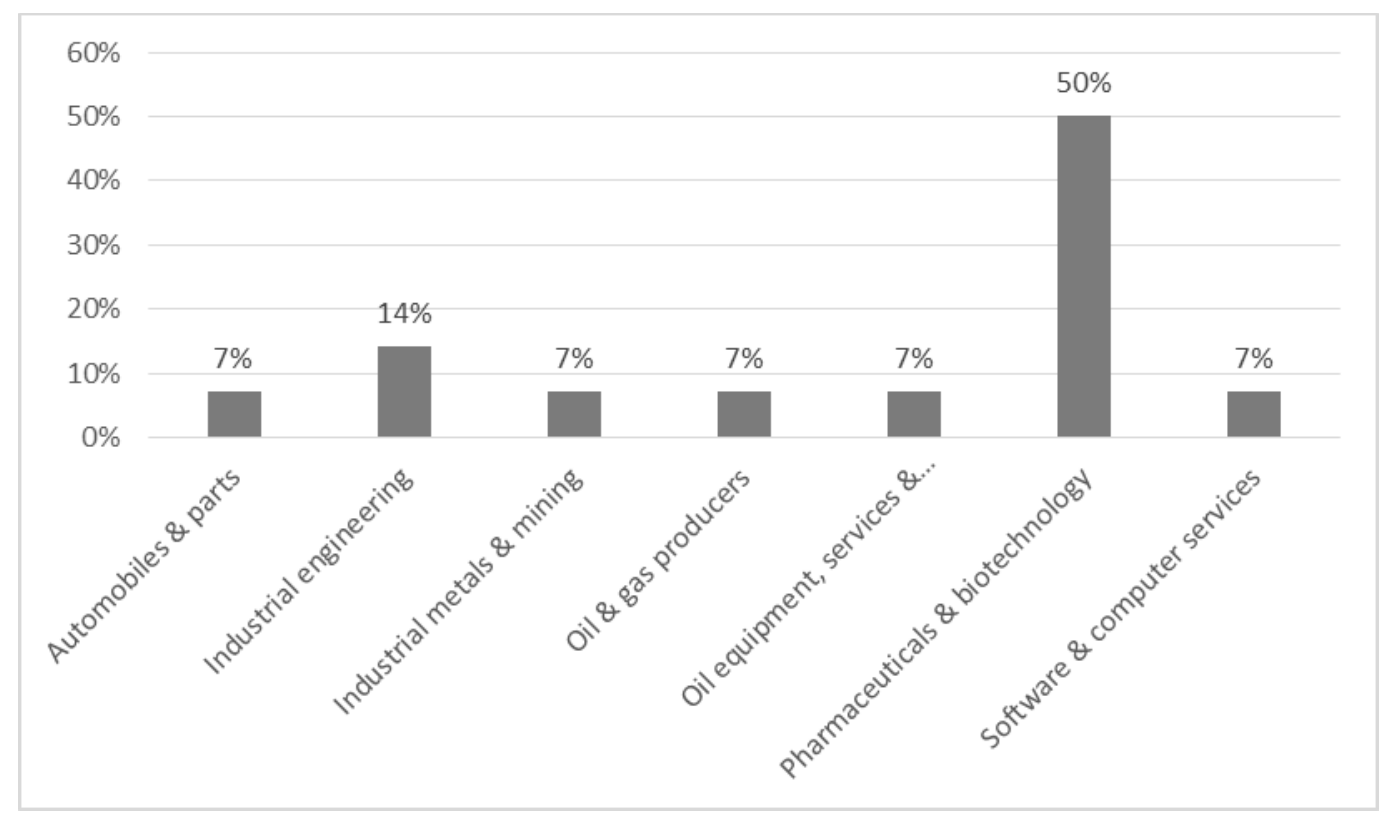

Figure 2: The most innovative Indian business groups by sector (Source: JCR, 2012)

From the comparison between China and India it seems that the Chinese business groups seems to be investing more in R\&D in sectors such as Automobile \& Parts, Construction \& Materials, Industrial Engineering and Industrial Metals \& Mining that tend to be more traditional. The thriving automobile industry in China is evident by Chinese firms' relentlessly pursuit of Western automotive assets (e.g. Geely Automobile recently acquired Volvo), by the popularity of capability-enhancing joint ventures (Zhao et al., 2005), by their long-term future oriented innovation (e.g. BYD Auto produces electric cars), by the innovatively increased global presence (e.g. Chery Automobile targets developing markets), and even through the emergence of copycats selling remarkably inexpensive cars (e.g. Shuanghuan). With their strong reverse-engineering capability, Chinese copycats excel in imitative innovation largely by mimicking designs and technologies from established firms, while adding new functions and own designs; however, they typically fail in deploying and utilizing these capabilities across borders (PWC, 2013).

By contrast, their Indian counterparts seem to have invested more in R\&D in sectors such as Pharmaceuticals \& Biotechnology and Industrial Engineering that tend to be more modern and dynamic. This evidence reflects the experience of Indian service firms (such as Infosys and Wipro) in global technology and consulting that have recently done very well. This is largely because these industries do not rely significantly on domestic infrastructure as they all started as the result of foreign outsourcing. They were then able to develop into worldwide service firms given the well-developed educational institutions coupled by good language skills and available labour. Nevertheless, India has substantial room to improve its education system (score 27.60; ranking 127) and to overcome the scarcity of trained workers in various manufacturing sectors (firms offering formal training score 15.90; ranking 96), indicated by its low tertiary education index (score 6.50; ranking 133) and low R\&D expenditure (score 30.90; ranking 30) compared with China. In this sense our findings support the view of Hoskisson et al. (2013) and Chin et al. (2013) by which the institutional development of China heavily characterized by the presence of state-owned-enterprises seem to have affected business groups sectoral innovation patterns by favouring a more conservative approach toward innovation where R\&D investments tend to target the more traditional sectors. As found by Mahmood and Mitchell (2004) these business groups facilitate innovation by providing institutional infrastructure, but at the same type discourage innovation in more modern and dynamic sectors by creating entry barriers for non-group firms and thereby inhibit the proliferation of new ideas. In China, for instance, business groups such as ChemChina in highly regulated, highly concentrated industries are largely protected by the government. Further, at corporate level, state-owned business groups in China tend to favour mergers and acquisitions as the means of diversification strategy, given the flexibility of staggering cash reserves and ease of access to state financial support. By contrast, Indian private business groups seem to be more receptive and dynamic despite India's relative poor infrastructure development. Some Indian business groups firms have ventured into more dynamic and modern sector producing more intangible and "weightless" products (Creative Output score 38.6; ranking 65; Creative Goods \& Services score 39.40; ranking 53) to overcome India's lack of infrastructure development. They have taken advantage of their natural resources and understanding of 
better market institutions often to develop innovation in global markets. Innovation linkages seem to be stronger in India then China (innovation linkages score 30.90; ranking 51) particularly in private firms given their advantage of newness, risk-taking culture, and greater desire to create their own brand-building and key technologies. More specifically, Indian firms possess superior leadership ability with their pro-Western education, culture, language, and training system, while Chinese private firms show strong entrepreneurship ability given the more economic freedom and enormous opportunities that characterises the country's market transition and business system change. Further, at corporate level, business groups in India firms frequently adopt a refocusing and restructuring corporate strategy to adjust their diversification strategy (Hoskisson et al., 2000) to their dynamic economy. This sectoral difference could be also explained on the basis of the data concerning the comparison of their institutional environments. If we look at the institutional development of these two countries, according to the Global Innovation Index Report 2013 they display a very different profile with China overperforming India in almost in every pillar (Political and Business Environment) except for the Regulatory Environment. The GII Score for China and India and their institutional subpillars as assessed by Global Innovation Index Report 2013 are outlined in the Table 6 below.

\begin{tabular}{|c|c|c|c|c|c|}
\hline \multicolumn{6}{|c|}{ Table 6: INSTITUTIONAL ENVIRONMENT } \\
\hline & \multirow[b]{2}{*}{$\begin{array}{l}\text { INSTITUTIONS } \\
\text { SUB PILLARS }\end{array}$} & \multicolumn{2}{|c|}{ CHINA } & \multicolumn{2}{|c|}{ INDIA } \\
\hline & & SCORE & RANK & SCORE & RANK \\
\hline \multicolumn{6}{|l|}{ INSTITUTIONS } \\
\hline \multirow{4}{*}{ Political environment } & Political environment & 39,20 & 126 & 44,40 & 108 \\
\hline & Political stability & 49,00 & 106 & 36,70 & 123 \\
\hline & Government effectiveness & 41,70 & 58 & 37,60 & 70 \\
\hline & Press freedom & 26,90 & 138 & 58,80 & 113 \\
\hline \multirow{4}{*}{$\begin{array}{l}\text { Regulatory } \\
\text { environment }\end{array}$} & Regulatory environment & 50,30 & 116 & 63,60 & 77 \\
\hline & Regulatory quality & 44,30 & 89 & 40,70 & 99 \\
\hline & Rule of law & 34,80 & 87 & 45,10 & 64 \\
\hline & $\begin{array}{l}\text { Cost of redundancy dismissal, } \\
\text { salary weeks }\end{array}$ & 27,40 & 118 & 15,80 & 74 \\
\hline \multirow[t]{4}{*}{ Business environment } & Business environment & 55,50 & 98 & 47,70 & 124 \\
\hline & Ease of starting a business & 67,50 & 118 & 62,40 & 128 \\
\hline & Ease of resolving insolvency & 38,50 & 73 & 28,30 & 104 \\
\hline & Ease of paying taxes & 60,50 & 98 & 52,50 & 118 \\
\hline
\end{tabular}

While China's ranking of its Political Environment (score 39.20; ranking 126) is significantly affected by the low ranking associated with Press freedom (score 26.90 ranking 138), its ranking in the Regulatory environment (score 50.30; ranking 116) is severely penalised by the Rule of law (score 34.80; ranking 87) and by the Cost of redundancy, dismissal and salary weeks (score 27.40; ranking 118). In China, while coercive isomorphism-government support has fostered the growth of state-owned enterprises, the country lacks accounting transparency. During market transition, business groups in China realized entrepreneurial opportunities, developed various strategies in terms of seeking political protection, cultivated ties with business associations, and in various innovative forms such as personnel enterprises, township and village enterprises, red-hat enterprises, private-owned enterprises or joint-owned enterprises. Within this context innovation in business groups in China seem to be facilitated by government effectiveness which create a sound institutional framework made by a relatively better political and business environment and that delivers a relatively lower regulatory quality that create effective barriers for new entrants by preserving the innovation potential of the more traditional sectors. More precisely, the lower ranking in the Regulatory environment in terms of Costs of redundancy, dismissal and salary weeks might prevent business groups' sectoral diversification and thus justify Chinese business groups more conservative approach. Through the support from the government, state-owned business groups in China can gain easy access to state/government controlled capital at low cost, and retain large cash reserves. This type of support makes them less inclined to embark into riskier investments. Chinese business groups, on the other hand, because of this legacy possess strong management expertise due in part to their budget-minded culture and tough accounting standards for private business groups wishing to access governmentally controlled loans. From an institutional perspective, benefiting from its heritage of British governance, India compares well in terms of Press freedom, Rule of law and the Cost of redundancy, dismissal and salary weeks. Financial risk-managing and controlling abilities are notable strengths of Indian business groups due to their 
appropriate corporate governance and maturity of the relevant rule of laws. These features support better innovation linkages often with international firms that translates into a different approach towards fostering innovation in more dynamic and innovative sectors.

By considering the geographical distribution of business groups' innovation in China and India, both countries tend to display different patterns. As illustrated in the Figure 3, by looking at the location of their administrative centers, Chinese business groups tend to be highly dispersed from a geographical point of view across several locations. The large majority is located between Beijing with $29 \%$ of the most innovative firms (Industrial Engineering, Oil \& Gas Producers, Construction \& Materials, Technology Hardware \& Equipment, Fixed Line Telecommunications), Guangdong with $11 \%$ of the most innovative firms (Automobile \& Parts and Technology Hardware \& Equipment) and Shanghai with 13\% of the most innovative firms (Industrial Engineering and Automobile \& Parts). However, innovative activity is highly concentrated along the Eastern coast, and especially in the South and in the three largest cities: Guangdong, Beijing and Shanghai (Crescenzi et al., 2012).

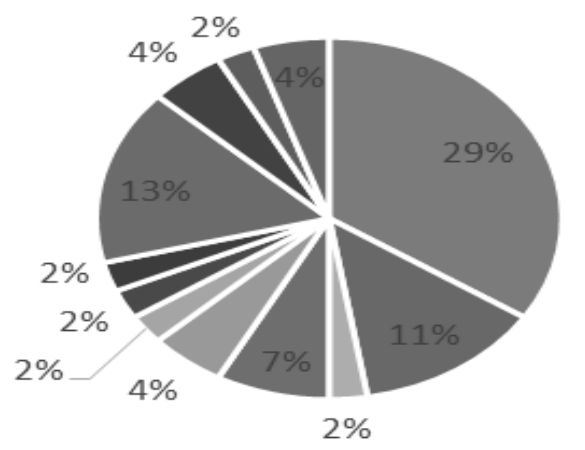

$$
\begin{aligned}
& \text { - Beijing (Beijing) } \\
& \text { - Henan (Jiaozuo) } \\
& \text { - Liaoning (Liaoning) } \\
& \text { - Sichuan (Chengbu) }
\end{aligned}
$$

$$
\begin{aligned}
& \text { - Guangdong (Guangzhou) } \\
& \begin{array}{l}
\text { - Jiangxi (Nanchang) Hebei (Baoding) } \\
\text { - Shandong (Zhucheng) }
\end{array} \text { - Shilin (Changchun) } \\
& \text { - Xinjiang (Wulumuqi) }
\end{aligned}
$$

Figure 3: China's most innovative areas

As illustrated in the Figure 4, by looking at the location of their administrative centers, Indian business groups tend to be geographically dispersed and concentrated in a few locations. The large majority of the most innovative firms is located between Maharashtra with 64\% of the most innovative firms (mostly Pharmaceuticals \& Biotechnology), New Delhi with 21\% (Software \& Computer services) Gujarat and Andhra Pradesh with respectively 7\% (both Pharmaceuticals \& Biotechnology) of the most innovative firms.

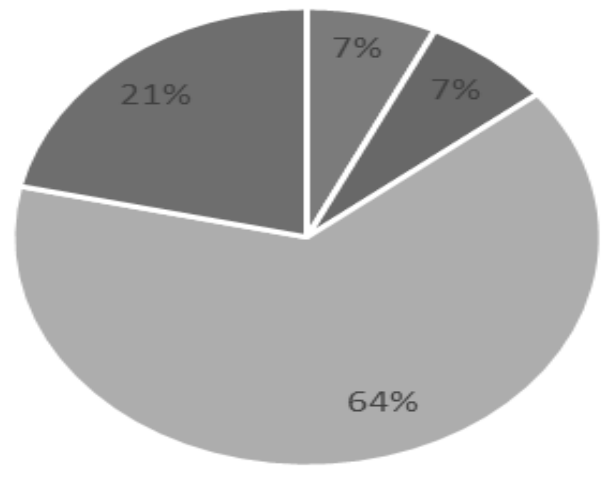

- Andhra Pradesh (Hyberabad)

- Gujarat (Ahmedabad)

- Maharashtra (Mumbai)

- New Delhi 
Figure 4: India's most innovative areas

The only business groups that have been present on the Scoreboard since 2009 are only the following five: Mahindra \& Mahindra (Automobile \& Parts); Bharat Heavy Electricals (Industrial Engineering); Cipla and Sun Pharmaceuticals (Pharmaceuticals \& Biotechnology); Infosys (Software \& Computer Services). These business groups tend to be located mostly in Mumbai and Maharashtra.

\section{Conclusion}

To date, apart from a few exceptions (Luo et al, 2011; Choi et al., 2011) almost no research has addressed the issue of the institutional interplay between business groups and innovation performance in China and India. As such, there was a valuable opportunity to conduct further research. Drawing on our recent work on business groups (Della Piana et al., 2012a; Della Piana et al., 2012b; Vecchi et al., 2013) and on innovation (Crowe et al., 2007; Vecchi and Brennan, 2009a; Vecchi and Brennan, 2009b) by endorsing an institution-based view (Peng et al., 2010; Luo et al., 2011) we assessed the innovation performance of business groups across China and India to identify their distinctive local innovation dynamics. In line with Hoskisson et al. (2013) the underlying assumption was that the dual effect of institutional development and infrastructure development in mid-range emerging economies would have profound consequences for firms' innovation performance.

Our findings support Hoskisson et al. (2013) argument that significant diversity of initial conditions, transition paths, and competitive outcomes have made it crucial to move away from the all-encompassing label of 'emerging economies'. As the heterogeneity of developed economies is being increasingly researched, there is the need to recognize that 'emerging economies' are also not homogeneous. More precisely in relation to the so called 'mid-range economies' further and country-specific considerations need to be made. According to Hoskisson et al. (2013) both China and India can be considered mid-range economies both characterised by high institutional development and low infrastructure development. By endorsing this institution-based framework our findings support that the dual effect of institutional development and infrastructure development in mid-range emerging economies not only have profound consequences for firms' internationalisation as found by Hoskisson et al. (2013) but also for their innovation performance.

In this sense our findings support the view of Hoskisson et al. (2013) by which the institutional development of China heavily characterized by the presence of state-owned-enterprises seem to have affected business groups' sectoral innovation patterns by favouring a more conservative approach toward innovation where R\&D investments tend to target the more traditional sectors. These findings are in line with Choi et al. (2011) who observe a lagged relationship between state ownership and innovation. According to the authors, because Chinese firms have a strong association with the state, this relationship may not be the result of direct state ownership itself. A certain level of state ownership is necessary to improve the innovation performance of firms, providing a positive signal to complementary economic institutions. This encourages effective monitoring and provides business connections and positive signalling, important factors for firms' $R \& D$ activities. The state functions as mediator between the market and the firm in an underdeveloped financial and labour market context. Within this context, state ownership thus offers greater protection to shareholders when the legal protection framework for investors is weak and uncertain. In addition, state ownership improves access to finance for Chinese firms, although it does impinge the ability of the corporate governance mechanism to cope with low-visibility technological capability.

By contrast, Indian private business groups seem to be more receptive and dynamic despite India's relative poor infrastructure development. Some Indian business groups firms have ventured into more dynamic and modern sector producing more intangible and "weightless" products to overcome India's lack of infrastructure development. They have taken advantage of their natural resources and understanding of better market institutions often to develop new innovation in global markets. Innovation linkages seem to be stronger in India then China particularly in private firms given their advantage of newness, risk-taking culture, and greater desire to build their own brands and key technologies. More specifically, Indian firms possess superior leadership ability with their pro-Western education, culture, language, and training system, while Chinese private firms show strong entrepreneurship ability given the more economic freedom and enormous opportunity that accompanies the country's market transition and business system change. 
While these findings are generally in line with prior research (Choi et al., 2011; Luo et al., 2011; Hoskisson et al., 2013), the novelty of this study stems from its explanation of innovation performance as a function of the institutional analysis (Hollingsworth, 2000) by mainly focussing on the formal institutions. In particular, this sectoral difference in R\&D investments can be also explained on the basis of the data concerning the comparison of their institutional sectors (Hollingworth, 2000). As a matter of fact, from the findings, it emerges, not only that China overperforms India in relation to all the Innovation Indexes but that their distinctive institutional environments tend to favour very different dynamics of local innovation. More precisely while China's regulatory environment tends to support a more conservative approach of business groups towards R\&D investments in traditional sectors, India's lack of infrastructures coupled by a more efficient regulatory environment tend to support more resourceful and creative approach. Consequently, given their respective pitfalls in their institutional sectors, the incentive for both Chinese and Indian firms to internationalise and gain from economies of scale and scope are very high. This partly explains the recent spurt in acquisitions by Chinese (Vecchi, 2013a, 2013b, 2014a, 2014b) and Indian firms (Kumar and Singh, 2008) in foreign markets.

These different approaches that seem deeply rooted in their different institutional settings also shape the geographical distribution of business groups' innovation performance across the two countries. In China by looking at the location of the business groups administrative centers of the most innovative firms, Chinese business groups tend to be highly dispersed across several locations. The large majority of the most innovative firms is located between Beijing, Guangdong and Shanghai. Indian business groups tend to be far less dispersed and all concentrated in a few locations. The large majority is located between Maharashtra, New Delhi, Gujarat and Andhra Pradesh. The different degrees of geographical concentration raise the question of whether co-location matter for formal knowledge collaboration (McKelevy et al., 2003) since the experience of China and India seem to support conflicting evidence. More precisely, the different degrees of geographical concentration of the most innovative business groups in China and in India are also reflected in the significantly different scores they have in terms of innovation linkages where China significantly underperforms India. Within this context, while the greater concentration of the Indian business groups seem to foster innovation collaborations, the greater dispersion of the Chinese business groups seem to be less conducive to innovation collaborations. Nonetheless, as noted earlier as Chinese companies become more competitive in innovation, they are increasingly bound to worry about potential obstacles to further innovation growth. Issues such as access to talent, retention of talent, rapid cost increases, difficulties in understanding market needs, inadequate infrastructure and innovation ecosystems and inadequate intellectual property protection are all key concerns for innovation in the future. These concerns are not only likely to increase pressure for stronger laws regarding intellectual property protection, but they may well lead to more innovative ways to conduct R\&D in cooperation with universities, institutes, and other entities. By contrast, Indian firms despite being deficient in financial, managerial and technological resources tend to develop distinctive capabilities by serving demanding and price-sensitive customers and operating in extremely challenging distribution environments. Such capabilities are often unique and call for resourcefulness - for example the Indian group Ranbaxy Laboratories by serving the needs for cheap drugs for the huge Indian market, developed into one of the world's most leading generic drug manufacturers. In the case of the pharmaceutical industry for instance, business groups have significantly benefited from exploiting market and institutional imperfections, such as the historical Indian patent law which enabled Indian companies to copy innovative molecules. In a similar fashion, when operating abroad, Indian pharmaceutical groups have benefited from capitalising on patent expirations of pharmaceutical drugs and the increased acceptance of outsourcing and offshoring by Western pharmaceutical firms.

The findings are relevant to all firms (from SMEs to large firms) wishing to set-up R\&D facilities in China or India. In particular given that most new multinational firms from emerging economies tend to be from these mid-range economies, examining their local innovation performance might offer new and valuable insights into how this heterogeneity of institutional contexts might affect business groups' behaviour. It also allows us to extend conceptual insights from the institution-based perspective. Cross-referencing data from the Global Innovation Index Report 2013 with the JCR database has been a fruitful exercise as it has allowed us to provide an accurate description of business groups' innovation performance in China and India and some in-depth insights of their local dynamics.

However, several methodological limitations need to be acknowledged. First, the Scoreboard relies on disclosure of R\&D investment in published annual reports and accounts. Therefore, companies which do not disclose figures for R\&D investment or which disclose only figures which are not material enough are not included in the Scoreboard. Due to different national accounting standards and disclosure practice, companies of some countries are less likely than others to disclose R\&D investment consistently. In some countries, R\&D costs are very often integrated with 
other operational costs and can therefore not be identified separately. Second, the focus of the Scoreboard on R\&D investment as reported in business group accounts means that the results can be independent of the location of the $R \& D$ activity. The Scoreboard indicates the level of $R \& D$ funded by companies, not all of which is carried out in the country in which the company is registered. The Scoreboard refers to all R\&D financed by a particular company from its own funds, regardless of where that $R \& D$ activity is performed. This last point is particularly important since one of the important aspects of studying local innovation dynamics is associated with the tracking of the movements of the tacit knowledge that prevails in such localized environments and that is mostly insulated from outside world. These localized innovation systems do not always correspond to well-defined innovation parameters such as R\&D expenditure or patents or publications. Third, the focus of our institutional analysis mainly concerns the formal institutions or the institutional sectors (Hollinghworth, 2000) that can more easily ascertained considering the data available, we would expect for instance that guanxi would play a major role in China and that might surely differ in India. Stemming from these limitations, future research could complement the perspective offered by our paper by trying to overcome these main methodological pitfalls by providing fine grained information on how informal institutional settings might affect innovation performance.

This paper contributes to the literature by revisiting and extending Hoskisson et al. (2013), with a particular focus on innovation performance of business groups from mid-range economies. Specifically, we have argued it is time to move beyond a simple dichotomy that divides the world into emerging and developed economies. Even within subcategories such as 'mid-ranged economies' there is a need to consider more fine-grained notions of institutional context with varying degrees of institutional development and infrastructure development. The findings from China and India provide an emblematic example as their differences in innovation performance contribute to a reinvigoration and extension of the life cycle of the agenda for strategy research in mid-range emerging economies. A better appreciation of the variety of institutional factors underpinning the different mid-range emerging economies can help develop understanding of the spectrum of business groups' governance models observed in these economies and their implications for innovation. It can also contribute to the development of a more fine-grained contextualized institutionbased view to business groups' governance in general. The findings lend themselves to some policy consideration. Despite China over-performing India in relation to all the Innovation Indexes, both countries could potentially learn from each other. China should change its regulatory environment to facilitate R\&D investments in more dynamic and modern sectors so to diversify its industrial base by strengthening its creative output. By contrast, India should improve its infrastructure and its educational system to facilitate a more pragmatic approach to innovation in the more traditional sectors. These would not be beneficial to business groups only but it could also bring remarkable benefits to firms of all sizes.

\section{Acknowledgments}

Funding has been received to support this work from the Marie Curie Programme.

\section{References}

Asakawa K., Som A. (2009). Internationalization of R\&D in China and India: Conventional wisdom versus reality. Asia Pacific Journal of Management, 25(3):375-394.

Baysinger, B.D., Kosnik, R.D., and Turk, T.A. (1991). Effects of board and ownership structure on corporate R\&D strategy. Academy of Management Journal, 34(1), 205-214.

Brown, T. E. and Ulijn, J. (2004). Innovation, entrepreneurship and culture: The interaction between technology, progress and economic growth. Cheltenham: Edward Elgar.

Carney, M., Gedajlovic, E., Heugens, P. P. M. A. R., van Essen, M., \& van Oosterhout, J. (2011). Business group affiliation, performance, context, and strategy: A meta-analysis. Academy of Management Journal, 54: 437-460.

Carney M., Gedajlovic E.,Yang X. (2009). Varieties of Asian capitalism: Toward an institutional theory of Asian enterprise. Asia Pacific Journal of Management, 26(3):361-380. 
Chacar, A, Vissa, B. (2005). Are emerging economies less efficient? Performance persistence and the impact of business group affiliation. Strategic Management Journal, 26(10), 933-946.

Chang, S., Chung, C. Mahmood, I.P. (2006). When and how does business group affiliation promote firm innovation? A tale of two emerging economies. Organization Science, 17(5), 637-656.

Chang, S.J. and Hong, J. (2002). How much does the business group matter in Korea? Strategic Management Journal, 23, 265-274.

Choi, S.B, Ha, S.H. and Williams, C. (2014) 'Institutions and broadband Internet diffusion in emerging economies: lessons from Korea and China', Innovation: Management Policy and Practice, 16(1): 2-18.

Cloodt, M., Hagedoorn, J. (2003). Measuring innovative performance: is there an advantage in using multiple indicators? Research Policy, 32(8), 1365-1379.

Crescenzi, R., Rodriguez-Pose, A., Storper, M. (2012). Territorial dynamics of innovation in China and India. Journal of Economic Geography, 12, 1055-1085.

Crowe, D., Vecchi, A., Brennan, L., and Coughlan, P. (2007). Manufacturing strategy and innovation in indigenous and foreign firms: an international study. International Journal of Manufacturing Technology and Management, 11(1), 327.

Cuervo-Cazurra A. (2006). Business groups and their types. Asia Pacific Journal of Management, 23(4): 419-437.

Della Piana, B., Nave, G., Gallucci, C. (2014). - Business Group Affiliation: Research gap and opportunities in Family Business Research, International Journal of Financial Studies (forthcoming).

Della Piana, B., Vecchi, A., Cacia, C. (2012a). Towards a better understanding of Family Business Groups and their key dimensions. Journal of Family Business Strategy, 3(3), 174-192.

Della Piana, B., Vecchi, A., Cacia, C. (2012b). Towards a better understanding of Family Business Groups from a crosscultural perspective. Paper presented at the 5th Annual EuroMed Conference of the EuroMed Academy of Business. Building New Business Models For Success Through Competitiveness and Responsibility. Edited by Demetris Vrontis, D., Yaakov Weber, Y., Kaufmann, R., Tarba, S. Published by EuroMed Press.

Della Piana, B., Vivacqua, E. (2012). Innovazione, clima organizzativo e differenze culturali: un'analisi esplorativa nel contesto dell'industria farmaceutica. Esperienze d'impresa, Vol.1, 107-127.

Dess, G.G., Beard, D.W. (1984). Dimensions of organizational task environments. Administrative Science Quarterly, 29(1), 52-73.

Dodgson M. (2009). Asia's national innovation systems: Institutional adaptability and rigidity in the face of global innovation challenges. Asia Pacific Journal of Management, 26:589-609.

Filatotchev I., Jackson G., Nakajima C. (2013). Corporate governance and national institutions: A review and emerging research agenda. Asia Pacific Journal of Management, 30(4): 965-986.

Forsman, H. (2011). Innovation capacity and innovation development in small enterprises. A comparison between the manufacturing and service sectors. Research Policy, 40(5), 739-750.

Gaur, A. S. and Kumar, V. (2009). International Diversification, Business Group Affiliation and Firm Performance: Empirical Evidence from India. British Journal of Management, 20(2), 172-186. 
Granovetter, M. (1994). Business groups. In: Smelser, NJ, Swederg, R. (Eds.). The Handbook of Economic Sociology. Pinceton University, Princeton, Russell Sage, New York, 453-475.

Griffith, R., Redding, S. and Van Reenen, J. (2000). Mapping the Two Faces of R\&D: Productivity Growth in a Panel of OECD Industries, CEPR Discussion Paper n. 2457.

Guillen, M.F. (2000). Business Groups in Emerging Economies: A Resource-Based View. Academy of Management Journal, 43(3), 362-380.

Hagedoorn, K., and Schakenraad, J. (1990). Inter-Firm Partnerships and Co-operative Strategies in Core Technologies. In C. Freemanand L. Soete (Eds.), New Explorations in the Economics of Technological Change. London: Printer.

Hollingsworth, J.R. (2000). Doing institutional analysis: Implications for the study of innovations. Review of International Political Economy, 7(4): 595-644.

Hoskisson, R. E., and Hitt, M.A. (1988). Strategic control systems and relative R\&D investment in large multiproduct firms. Strategic Management Journal, 9(6), 605-621.

Hoskisson, R.E., Eden, L., Lau, C.M., and Wright, M. (2000). Strategy in emerging economies. Academy of Management Journal, 43(3), 249-268.

Hoskisson, R.E., Wright, M., Filatotchev, I., and Peng, M.W. (2013). Emerging Multinationals from Mid-Range Economies: The Influence of Institutions and Factor Markets. Journal of Management Studies, 50(7), 1295-1321.

Hsieh, T.J., Yeh, R.S., and Chen, Y.J. (2010). Business group characteristics and affiliated firm innovation: The case of Taiwan. Industrial marketing management, 39(4), 560-570.

Kedia, B. L., Mukherjee, D., and Lahiri, S. (2006). Indian business groups: Evolution and transformation. Asia Pacific Journal of Management, 23(4): 559-577.

Keister, L.A. (1998). Engineering Growth: Business Group Structure and Firm Performance in China's Transition Economy. American Journal of Sociology, 104 (2), 404-40.

Khanna, T., Palepu, K. (2000). Is group affiliation profitable in emerging markets? An analysis of diversified Indian business groups. The Journal of Finance, 55(2), 867-891.

Khanna, T., Rivkin, J.W. (2001). Estimating the performance effects of business groups in emerging markets. Strategic Management Journal, 22(1), 45-74.

Khanna, T., Yafeh, Y. (2007). Business Groups in Emerging Markets: Paragons or Parasites? Journal of Economic Literature, Vol. XLV, 331-372.

Kim, H., Bae, J., Bruton G.D. (2012). Business groups and institutional upheaval in emerging economies: Corporate venturing in Korea. Asia Pacific Journal of Management, 29(3):729-752.

Kim, H., Hoskisson, R.E., Tihanyi, L., and Hong, J. (2004). The evolution and restructuring of diversified business groups in emerging markets: The lessons from chaebols in Korea. Asia Pacific Journal of Management, 21(1-2), 25-48.

Kumar, V., Singh N. (2008). Internationalization and Performance of Indian Pharmaceutical Firms. Thunderbird International Business Review, 50(5), 321-330.

Lau, C.M., Bruton, G.D. (2008). FDI in China: What we know and what we need to study next. The Academy of Management Perspectives, 22(4), 30-44. 
Lawrence, P. R., Lorsch, J.W. (1969). Developing Organizations: Diagnosis and Action. Addison-Wesley Longman, Incorporated.

Lu, H., Tan Y., and Huang H. (2013). Why do venture capital firms exist: An institution-based rent-seeking perspective and Chinese evidence. Asia Pacific Journal of Management, 30, 921-936.

Luo, Y, Sun, J, and Wang, Lu, S. (2011). Comparative strategic management: An emergent field in international management. Journal of International Management, 17(3), 190-200.

Luo, Y., Tsang, E. W. K., and Peng, M.W. (2008). Knowledge management and innovation strategy in the Asia Pacific: Toward an institution-based view. Asia Pacific Journal of Management, 25(3), 361-374.

Lyles, M. A., and Salk, J.E. (1996).Knowledge acquisition from foreign parents in international joint ventures: An empirical examination in the Hungarian context. Journal of International Business Studies, 27(5), 877-903.

Mahmood, I.P., Mitchel, W. (2004). Two Faces: Effects of Business Groups on Innovation in Emerging Economies. Management Science, 50(10), 1348-1365.

McKelvey, M., Alm, H., \& Riccaboni, M. (2003). Does co-location matter for formal knowledge collaboration in the Swedish biotechnology-pharmaceutical sector? Research Policy, 32(3), 483-501.

McKinsey and Company (2009), NASSCOM and McKinsey "Perspectives 2020". The report is available at http://www.nasscom.in/perspective-2020-nasscom-mckinsey-study.

Narayanan, V.K. , Fahey, L. (2005). The Relevance of the Institutional Underpinnings of Porter's Five Forces Framework to Emerging Economies: An Epistemological Analysis. Journal of Management Studies, 42(1), 207-223.

North, D.C. (1990). Institutions, Institutional change, and economic performance. Cambridge, MA: Harvard University Press.

North, D.C. (1991). Institutions. Journal of Economic Perspectives, 5 (1), 97-112.

Peng M.W. (2002). Towards an Institution-Based View of Business Strategy. Asia Pacific Journal of Management, 19(23):251-267.

Peng M.W., Delios A. (2006). What determines the scope of the firm over time and around the world? An Asia Pacific perspective. Asia Pacific Journal of Management , 23(4):385-405.

Peng, M.W. (2003). Institutional transitions and strategic choices. Academy of Management Review, 28 (2), 275-296.

Peng, M.W. and Pleggenkuhle-Miles, E.G. (2009). Current debates in global strategy. International Journal of Management Reviews, 11(1), 51-68.

Peng, M.W., and Jiang, Y. (2010). Institutions behind family ownership and control in large firms. Journal of Management Studies, 47(2), 253-273.

Price Waterhouse Cooper (2013). An Emerging Innovation Power: 2013 China Innovation Survey. The report is available at http://www.strategyand.pwc.com/global/home/what-we-think/reports-white-papers/article-display/emerginginnovation-power

Ramaswamy K., Li M., Petit, B. S. (2012). Why do business groups continue to matter? A study of market failure and performance among Indian manufacturers. Asia Pacific Journal of Management, 29(3): 643-658. 
Sandven, T., and Smith, K. (1997). Understanding R\&D Indicators: Effects of Differences in Industrial Structure and Country Size. IDEA Paper 14, STEP Group Oslo.

Soh P. H., Yu J. (2010). Institutional environment and complementary assets: Business strategy in China's 3G development. Asia Pacific Journal of Management, 27(4):647-675.

Tong T.W., Reuer, J.J., and Peng, M.W. (2008). International joint ventures and the value of growth options. Academy of Management Journal, 51(5), 1014-1029.

Vecchi, A. (2014a). Evidence from Chinese acquisitions of Made in Italy firms in the luxury sector - The acquisition of a traditional luxury firm. European Journal of Management, 14 (1):113-124.

Vecchi, A. (2014b). The allure of brand heritage - The Chinese acquisition of an Italian luxury pen maker. Journal of International Business and Economics, 14 (1): 97-108.

Vecchi, A., Della Piana, B., Cacia, C. (2014c). The internationalisation of family business groups: a cross-cultural perspective, AIB Proceedings, Vancouver, Canada.

Vecchi, A. (2013a). The impact of Chinese Acquisitions on the Made in Italy Luxury Sector: A systematic review of the literature. California Business Review, 1 (2): 39-52.

Vecchi, A. (2013b). The impact of Chinese Acquisitions on the Made in Italy Luxury Sector. Journal of International Finance and Economics, 3 (2): 75-82.

Vecchi, A., and Brennan, L. (2009a). A cultural perspective on innovation in international manufacturing. Research in International Business and Finance, 23(2), 181-192.

Vecchi, A., and Brennan, L. (2009b). Supply chain innovation for short-life products: a preventive assessment of RFID deployment and implementation. International Journal of Business Innovation and Research, 3(5), 535-554.

Vecchi, A., Della Piana, B., and Cacia, C. (2013). A cross-cultural perspective of family business groups. Journal of International Business and Economics, 13(2), 93-108.

Wan, W.P. and Hoskisson, R.E. (2003). Home country environments, corporate diversification strategies, and firm performance. Academy of Management Journal, 46(1), 27-46.

Wright, M., Filatotchev, I., Hoskisson, R.E., Peng, M.W. (2005). Strategy Research in Emerging Economies: Challenging the Conventional Wisdom. Journal of Management Studies, 42(1), 1-33.

Zattoni, A., Pedersen, T., and Kumar V. (2009). The Performance of Group-affiliated Firms during Institutional Transition: A Longitudinal Study of Indian Firms. Corporate Governance: An International Review, 17(4), 510-523.

Zhao, Z., Anand, J., and Mitchell, W. (2005). A Dual Networks Perspective on Inter-Organizational Transfer of R\&D Capabilities: International Joint Ventures in the Chinese Automotive Industry. Journal of Management Studies, 42(1), $127-160$. 